\title{
ASSESSING THE RELEVANCE OF ASSISTIVE TECHNOLOGIES FOR PERSONS WITH DISABILITIES IN HIGHER LEARNING INSTITUTIONS: A CASE OF UNIVERSITY OF DAR ES SALAAM IN TANZANIA
}

\author{
Josephine C. Ngonyani ${ }^{11}$, \\ Cosmas B. Mnyanyi ${ }^{2}$ \\ 1Tutorial Assistant, \\ Tanzania Public Service College, \\ Tanzania \\ ${ }^{2}$ Senior Lecturer in Educational Psychology and \\ Special Needs Education, \\ The Open University of Tanzania, \\ Tanzania
}

\begin{abstract}
:
This paper assesses the relevance of assistive technology (AT) used by persons with disabilities enrolled in higher learning institutions (HLIs) in Tanzania. Assistive technology in its general sense is meant to support persons with disabilities (PWD) in managing their daily activities, including participation in teaching and learning. The study was descriptive in nature and used a cross-sectional research design. A total of 173 respondents participated in the study; 18 Management officials, 47 students, 35 trainers, 40 Dar-es-Salaam University Students Organisation (DARUSO) leaders, and 33 PWD. Among the 33 PWD; (10) visually impaired, (5) low vision, (7) physically impaired, (3) albinism, (7) hearing impaired, and (1) speech impaired. The study revealed that AT was provided conforming to the kind of a disability and that training was for new AT users. The training covered topics related to simple maintenance and repair of AT. The challenge was related to the shortages of AT experts and AT courses for training, caretakers and other professionals. The study recommends the establishment of AT courses for developing a cadre of AT specialists for conducting rehabilitation services.
\end{abstract}

Keywords: assistive technology, persons with a disability, higher learning institutions

\section{Introduction}

Assistive technology refers to any facility, specifically made or commonly available, that is used by PWD for participation, to guard, support, train, measure, or substitute for body

i Correspondence: email josephinecn17@gmail.com, cosmas.mnyanyi@yahoo.co.uk 
functions, structures, and activities, or to prevent shortages, activity limitations, or participation barriers. It comprises hardware (devices, equipment, instruments) and software (WHO, 2015). According to the national policy on disability of 2004, disability is "loss or limitation of opportunities to take part in the normal life of the community on an equal level with others due to physical, mental or social factors", and that PWD is "an individual whose prospects of obtaining and retaining an employment are greatly reduced due to known physical, mental or social factors" (the United Republic of Tanzania, 2004).

Among the fundamental human rights that require protection for everyone is education (UNESCO, 2009). Education is one of the priorities that Tanzania has taken to create a knowledgeable society that helps in building a strong and developed nation (URT, 1998). Previously PWD was socially, physically, and academically isolated, however, various initiatives are ready to enhance and support the right to education for PWD by promoting responsiveness and inspiring the distribution of decent practices. To support this call, Tanzania has enacted several rules, guidelines, policies, and documents concerning PWD including education for all (EFA), Tanzania PWD act of 2010, and Universal Primary Education (UPE) (Kisanga et al., 2018). According to Tungaraza (2012), these initiatives led to the establishment of inclusive education in Tanzania. The National Higher Education Policy (The United Republic of Tanzania, 2007) emphasizes inclusive education and directs the HLIs to design and build the infrastructures that are easily accessible by PWD and provide necessary facilities, loans, and support services to improve their participation.

In Tanzania, the first special education school "Wilson Carlile School for Blind Boys" was established in 1950 by a charitable organization to accommodate visually impaired students (Tungaraza, 2014) the teachers were on job trained only for a specified disability. After being employed, instead of applying skills and knowledge learned from college, they were learning how to handle various lecture room themselves since they were not fully prepared and on-job trainings were limited (Mnyanyi, 2009).

The rising compassion to the needs of PWD and increase in their enrollment at the University of Dar-es-Salaam (UDSM) contributed to the establishment of the department of special education unit in the academic year 1978-1979 to support visually impaired students who were enrolled in that academic year. Later in the 1980s, the unit received students with other impairments such as albinism, physical impairment, and hearing impairment (Mwaipopo et al., 2011). Their number increased to 238 students in the academic year 2010-2011. The unit had two sign language interpreters, three trained transcribers, and non-trained part-time readers and note-takers. The Tanzania Education Authority delivered some AT to the department such as electronic note-takers, special scanners, and low vision devices which were only for visually impaired students (Njewele et al., 2011). Furthermore, Dar es Salaam College of Education (DUCE) constituent, a special unit was established in 2005 whereby AT provided to the PWD were white canes tape recorders, magnifiers, computers with JAWS software, talking scientific calculators, and Perkins Braille (DUCE, 2018). As demonstrated in Table 1 In the academic year 2019-2020 a total number of 160 PWD were supported by the University. 
Students may benefit from technology if their instructors make effort to train them to use it effectively (Batorowicz, Missiuana, \& Pollock, 2012; Lee \& Vega, 2005; Marino, Marino, \& Shaw, 2006; Michaels \& McDermott, 2003).

Table 1: Students with disabilities enrolled at UDSM and DUCE Constituent in the Academic year 2019/2020 and respective AT

\begin{tabular}{|c|c|c|c|}
\hline No. & $\begin{array}{l}\text { Category of } \\
\text { Disability }\end{array}$ & $\begin{array}{c}\text { Number of } \\
\text { Students }\end{array}$ & $\begin{array}{l}\text { Relevant Assistive } \\
\text { Technology Needed }\end{array}$ \\
\hline & Albinism & 6 & $\begin{array}{l}\text { Closed-circuit television (CCTV), Optical character } \\
\text { recognition, Electronic note-taker, and Handheld } \\
\text { magnifier }\end{array}$ \\
\hline & $\begin{array}{l}\text { Challenges and } \\
\text { other special needs }\end{array}$ & 3 & Wheelchairs and other related special services \\
\hline & Hearing-impaired & 34 & $\begin{array}{l}\text { Assistive listening devices (ALDs), Digital hearing } \\
\text { aids, and personal amplifiers. }\end{array}$ \\
\hline & Low vision & 50 & $\begin{array}{l}\text { Closed-circuit television (CCTV), Optical character } \\
\text { recognition, Electronic note-taker, and Handheld } \\
\text { magnifier }\end{array}$ \\
\hline & Physical impaired & 32 & Clutches, Wheelchairs \\
\hline & Speech impaired & 01 & $\begin{array}{l}\text { Alerting devices, Augmentative and Alternative } \\
\text { Communication (AAC) devices example speech to } \\
\text { text software and verbal cues }\end{array}$ \\
\hline & Visual impaired & 34 & $\begin{array}{l}\text { Perkins braille, braille papers, Cut-sheet braille } \\
\text { papers, Braille note, Braille display, Braille embosser, } \\
\text { White cans, Optical character recognition systems, } \\
\text { electronic notetaker, computers with software and } \\
\text { talking programs e.g JAWS and NVDA, Voice } \\
\text { recorder, talking watch, talking calculators, electronic } \\
\text { talking dictionaries and Audiobooks. }\end{array}$ \\
\hline \multicolumn{2}{|c|}{ Total } & 160 & \\
\hline
\end{tabular}

Source: Field data, 2020.

Promotion of the use of AT among PWD goes together with the delivery of training to students, their parents, and teachers respectively. A student with a disability can be independent to get in lessons, access to library services, read, write organize their activities, and works if training on services related to the use of AT is provided (MacArthur, Ferretti, Okolo, \& Cavalier, 2001; Mull \& Sitlington, 2003). Training makes a student not only become proficient with AT but also environmental aspects that endlessly support students on AT usage during the course of their learning processes (Specht, Howell, \& Young, 2007). Assistive technology and its associated facilities must be combined with context-appropriate coaching from competent trainers since learners' effective application of AT is directly connected to expertise, understanding, and characters of special education trainers (Michaels \& McDermott, 2003; Specht, Howell, \& Young, 2007; Okolo \& Diedrich, 2014). To continually support trainers on AT usage during PWD life in HLIs, pieces of training can be not only just a few workshops but also 
professional development opportunities (Lee \& Vega, 2005; Michaels \& McDermott, 2003).

Effective training during the course of educational or professional development opportunities in various institutions, may increase trainers' utilization and understanding of AT (Flanagan, Bouck, \& Richardson, 2013; Lee \& Vega, 2005). Generally, trainers and specifically special education trainers must be used to AT and instructional technology to implant this technology to both within their instruction and in numerous social settings when they interact PWD (Chmiliar, 2007; Chmiliar \& Cheung, 2007; Flanagan, Bouck, \& Richardson, 2013).

The main purpose of this study was to assess the relevancy of AT used by PWD in HLIs in Tanzania. This objective was one of the components of a descriptive study that examined the use of AT for PWD in HLIs in Tanzania, A case of university of Dar es Salaam. Specifically, the study focused on the relevancy of AT in terms of their usefulness, suitability, training, and expertise. It further looked at policy on AT use in HLIs, challenges on AT use, and solutions to those challenges.

\section{Methodology}

\subsection{Research questions}

- How does the available AT useful to the PWD?

- Do the available AT suitable to the users?

- Is there any training on the use of AT at UDSM?

- Are there any experts of AT at UDSM?

- Is there any national education policy specifically for PWD in HLIs in Tanzania?

- What are the challenges to the use of AT among PWD in HLIs in Tanzania?

- What are the solutions to the challenges among PWD through the use of AT?

\subsection{Study design}

The study was descriptive in nature because it was sought to come up with actual answers concerning the relevancy of AT in HLIs and adopted a case study design. After all, only UDSM was selected among all HLIs. Both primary and secondary data collection methods were employed to collect data from individuals, observations, and documents. The study was dominated by a qualitative approach and supplemented by a quantitative approach wherever necessary.

\subsection{Study site}

The target was HLIs, where UDSM Mwalimu Nyerere campus and DUCE its constituent was focused. This choice was made because this University is the oldest higher learning institution in Tanzania, rich in information for the study, and easily accessible. 


\subsection{Target population}

The target population involved 173 persons directly linked to the AT usage among PWD at UDSM including students with and without disabilities, and DARUSO leaders, trainers, and management.

\subsection{Sample size and sampling procedure}

Depending on what a researcher wants to do, the purpose of the inquiry, what is useful, credible, and what can be done with available time and resources, Patton (1990) suggests both purposely and randomly sampling methods to be used to select the respondents. The respondents included 18 management personnel who manages the special education unit and all supporters, 80 students, 35 trainers, and 40 DARUSO leaders. Among 80 students, 33 of them were PWD that includes10 visually impaired, 05 low vision, 07 hearing impaired, 03 Albino, 07 Physical impaired, and 01 speech impaired. Table 2 summarises the sample size of the study, and the tools employed.

Table 2: Sample size of the study

\begin{tabular}{|l|c|c|c|c|c|}
\hline Category & Sampling Methods & Male & Female & Total & Tools \\
\hline Management & Purposely & 09 & 09 & 18 & Interview \\
\hline Students & Purposely and Randomly & 39 & 41 & 80 & Questionnaires \\
\hline Trainers & Randomly & 18 & 17 & 35 & Questionnaires \\
\hline DARUSO leaders & Randomly & 22 & 18 & 40 & FGD \\
\hline Total & & $\mathbf{8 8}$ & $\mathbf{8 5}$ & $\mathbf{1 7 3}$ & \\
\hline
\end{tabular}

Source: Field Data, 2020.

\subsection{The instruments}

In this study, the questionnaire, interview, Focus Group Discussion (FGD), observation, and documentary review were used. A questionnaire was used to collect data from students and trainers, an Interview was scheduled for the management, and FGD was used to collect data from DARUSO leaders. Furthermore, observation was used to collect data concerning the relevancy of AT in terms of suitability and usefulness of physical infrastructure, support services and other facilities around UDSM in particular. Also, a Documentary review was done by tracking and reviewing various documents including students By-laws, an inventory of available AT for PWD, students' accommodation guidelines, and other documents related to AT and PWD at UDSM.

\subsection{Data analysis}

Quantitative data were analyzed by Microsoft Excel 2010 and qualitative data were analyzed based on their content. 


\section{Results and discussion}

\subsection{Demographic characteristics of the respondents}

\subsubsection{Gender}

Of the 173 respondents interviewed in this study, eighty-eight (50.9\%) were males and eighty-five (49.1\%) were females. Only a slight difference was noticed between male and female participants. This implies that the study was bias-free. Table 3 shows the results.

Table 3: Respondents' gender

\begin{tabular}{|l|c|c|c|}
\hline Gender & Male & Female & Total \\
\hline Respondents & 88 & 85 & 173 \\
\hline Frequency (\%) & $50.9 \%$ & $49.1 \%$ & $100 \%$ \\
\hline
\end{tabular}

\subsubsection{Respondents working experience}

Fifteen $(46 \%)$ of respondents had working experience below 5 years, thirteen(39\%) of respondents had working experience between 6-10 years, five (15\%) of respondents had working experience between 10-15 years, and no respondents working more than 16 years observed. This shows that majority of respondents had adequate experience with the institution enough to provide relevant information to the study. Figure 1 shows the results.

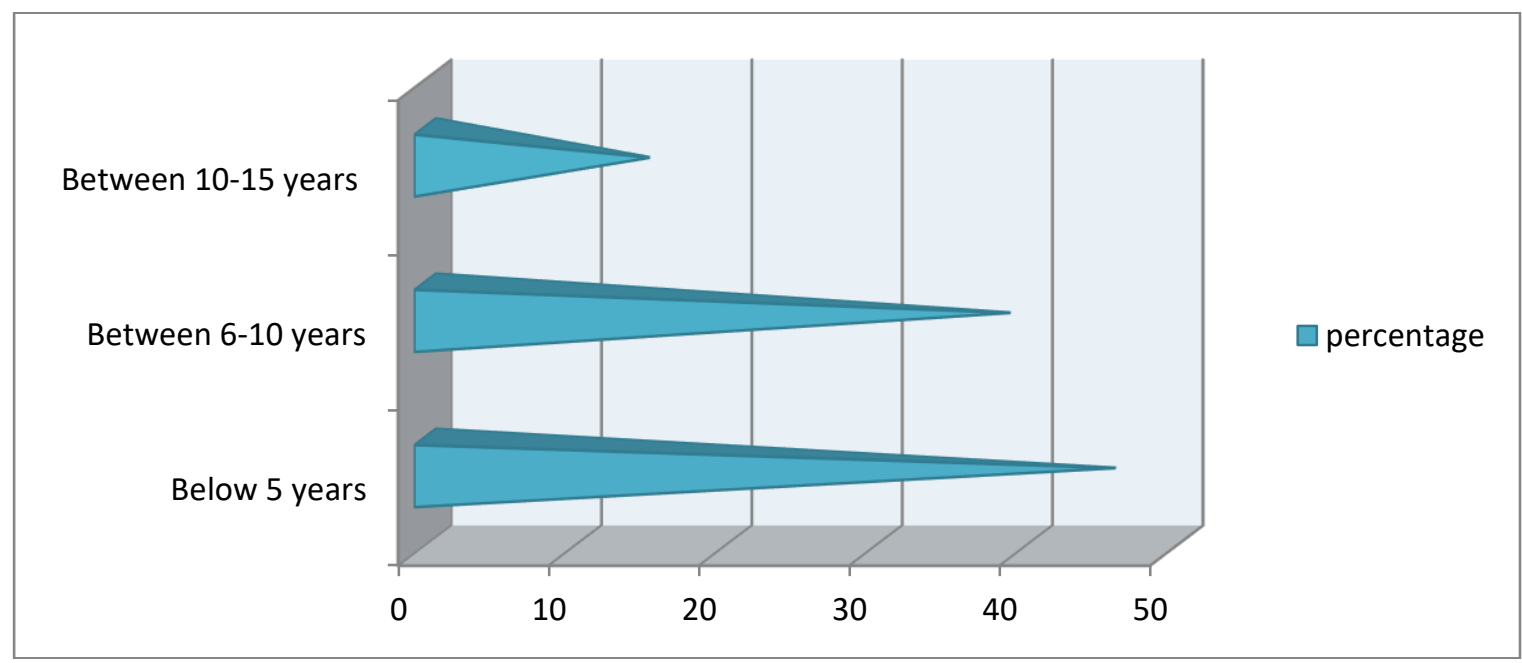

Figure 1: Respondents working experience

\subsubsection{Respondents' year of study}

Fifty-four (45\%) of respondents were between 2-3 years, forty-five (37\%) of respondents were below 2 years, twenty-one (18\%) of respondents were in 3-4 years and there were no respondents with more than 4 years. This shows that the researcher considered presentation from different years of study which makes information gathered bias-free. Figure 2 below shows the result. 


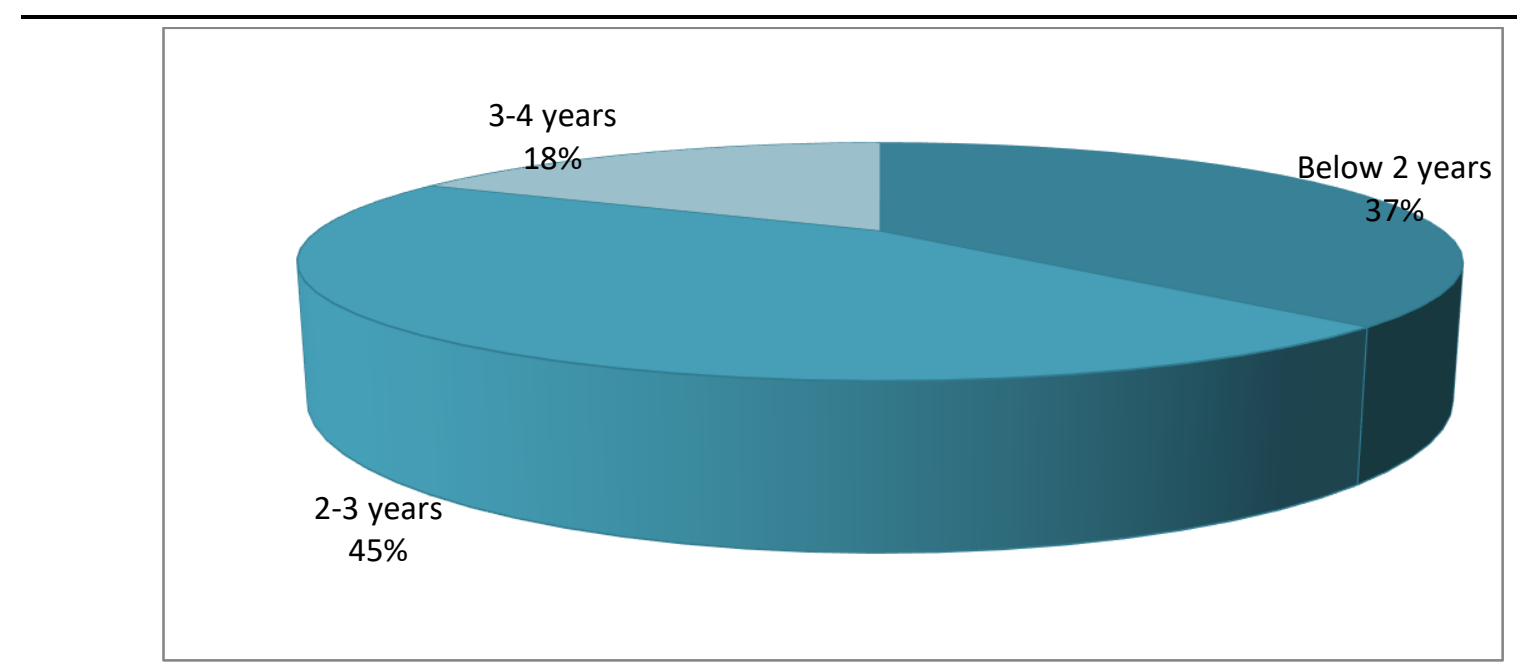

Figure 2: Respondents' years of study

\subsection{Usefulness of the available AT}

This defines how a certain feature in the AT helps or blocks the accomplishment of the difficult tasks 'usability' and how the user could reach their objectives with a particular AT support 'usefulness' (Lai, 2016). The objectives can be an actual performance of a valued activity or predictable achievement including safety, effort, and time-saving, increase confidence, independence, reduced stress, and embarrassment related to the task performance. The available AT was observed and examined to see if it helped the consumers to reach their goals, and revealed that AT was useful to some extent, and whenever unsuccessful there were some factors to the failure such as faults in some devices. Likewise, Ngonyani (2021) added more causes of AT failure such as deficiency of related support services, non-inclusive working environment (experts, training and the structure of premises) that was not prepared to support the AT functionality. On top of that, Krantz (2012) and Lai (2017) revealed AT adaptability as a factor that affected its usefulness; that includes how the AT was customized for its intended use, if the intended user was ready to accept and use it, if it was accessible in the right condition and if portable or fixed. The study revealed that a very small mistake could risk the usefulness and decrease the level of safety of an AT. If it did not work as intended it could not only disturb the performance but also have other effects example tape recorders and electronic note-takers could be affected by power interference or limited storage in some recorders, it might be full while a student still thinks that it continues to record. This affects the AT usefulness. Therefore, by understanding and training to use the AT helped the PWD to identify some errors during AT usage and accomplished the tasks with minimum errors.

\subsection{Suitability of the available AT}

The suitability of an AT depends on both: the desire or acceptability of the user and an attribute of the AT itself as if functions properly, safely, reliably, tailor-made, competent, appropriate, if it fits and satisfactory (McCreadie 2003; Bagon et al., 2018; Campbell et al., 2006). It was observed that before purchasing the AT, first the needs of the PWD were considered and highlighted in the acquisition document by the special education needs 
unit (SENU), and then the inventory list was prepared. Sometimes the acquisition process was too long due to some reasons including lack of funds therefore the gap was replaced by a provision of alternative AT that could not satisfy all user needs. There was also a possibility that the AT in question was incorrectly judged as it could or could not accomplish the intended task. This could have interfered with the suitability of the AT. Furthermore, Wessels et al. (2003) stressed that a very minor match between the AT and the user might influence whether the AT fits or not. Persons with disabilities must be always ascertained how, with whom, where, and when the AT can be provided most effectively. More than that the trainers should document each PWD's characteristics when using the AT and provide technical support, new methods to use it, listening carefully to users' feedback, and comment if the device lessens or fully eliminate deficiencies encountered by the PWD during the learning process. Also, the PWD should be enlightened or updated with information concerning new emerging sophisticated AT that perform better than the device that was being used at that time. This could assure PWD with more suitable options to fulfill their desires.

\subsection{Training on AT and their usage}

A Successful application of AT is associated with the understanding, skills, and nature of special education teachers (Michaels \& McDermott, 2003). When asked if there was training on the use of AT, all hundred and seventy-three respondents $(100 \%)$ responded "YES" and none said "NO". However, when it came to the question, to what extent training was provided, the study discovered that forty-three (63\%) said they were trained once a year normally when the semester begins, twenty-four ( $35 \%$ ) 2-4 times a year, one( $2 \%$ ) 4-6 times a year and none of them answered more than 6 times a year. Generally, pieces of training provided per year were not enough to meet the actual demand arising from the technology change and the fact that new students with disabilities continued to be enrolled and thus frequently training was needed. Figure 3 illustrates the result.

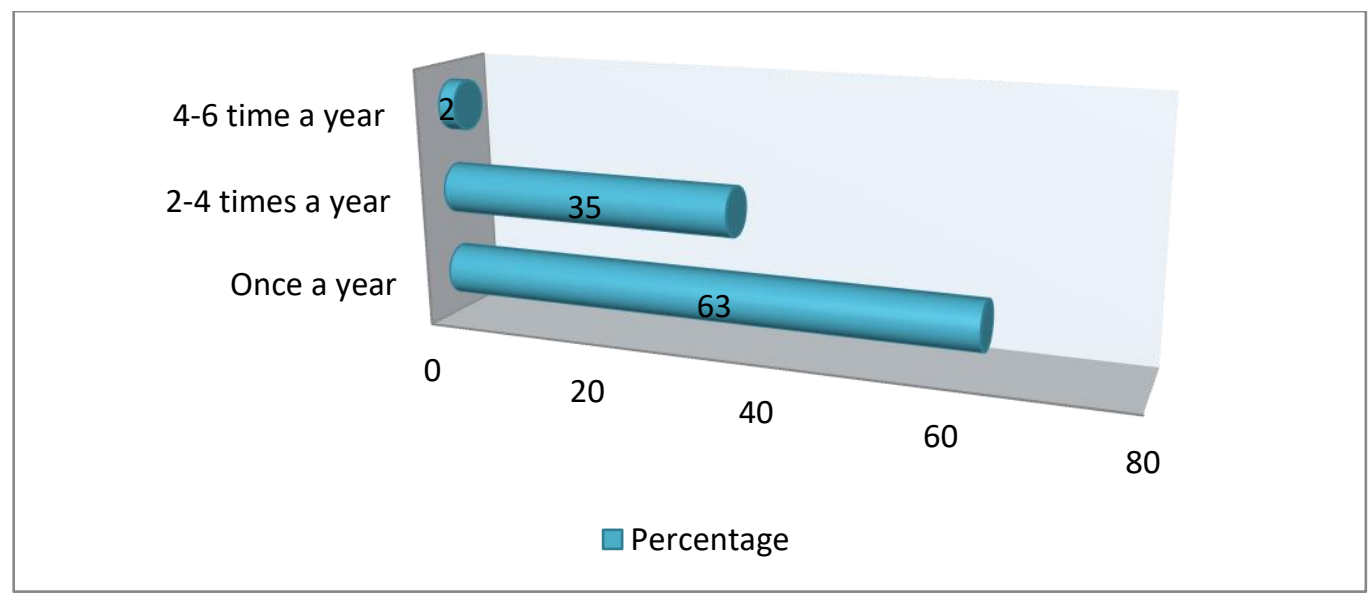

Figure 3: Extent by which Training on AT and their usage is provided

(Source: Field data, 2020.) 


\subsection{Availability of AT expertise}

Lack of technical instructors in HLIs may hinder trainers' ability to use AT effectively (Chiang \& Jacobs, 2010). Without effective technical support, trainers cannot solve technology-related matters. However, a trainer will have a chance to effectively use AT with the presence of a strong support system that comprises of AT team, mentor, or a colleague with relevant AT knowledge or experience (Campbell et. al., 2006). When asked about the presence of AT expertise, eighty-one (94\%) respondents said "NO" and only five $(6 \%)$ said "YES". Figure 4 illustrates the result. This means that there were no experts in the institution for installation, training, repair, and maintenance of AT, and those who agreed thought their trainers were AT experts. One respondent stated:

"We do not have permanent internal AT experts, we normally request the AT professionals from private sectors whenever a new device is bought or maintenance of the faulted ones is needed. This is very costly. Also no college in Tanzania is specialized specifically for training and producing AT experts."

The experts were normally outsourced from external providers when there was a need for installing a new purchased AT, training to both trainers and PWD, and if the failure of an AT occurred. Also, there was no workshop reserved for the maintenance and repair of AT. It could be helpful to both PWD and their trainers if the HLIs guaranteed the presence of AT technical support or an expert who would be available on time to solve technical problems in case they occurred.

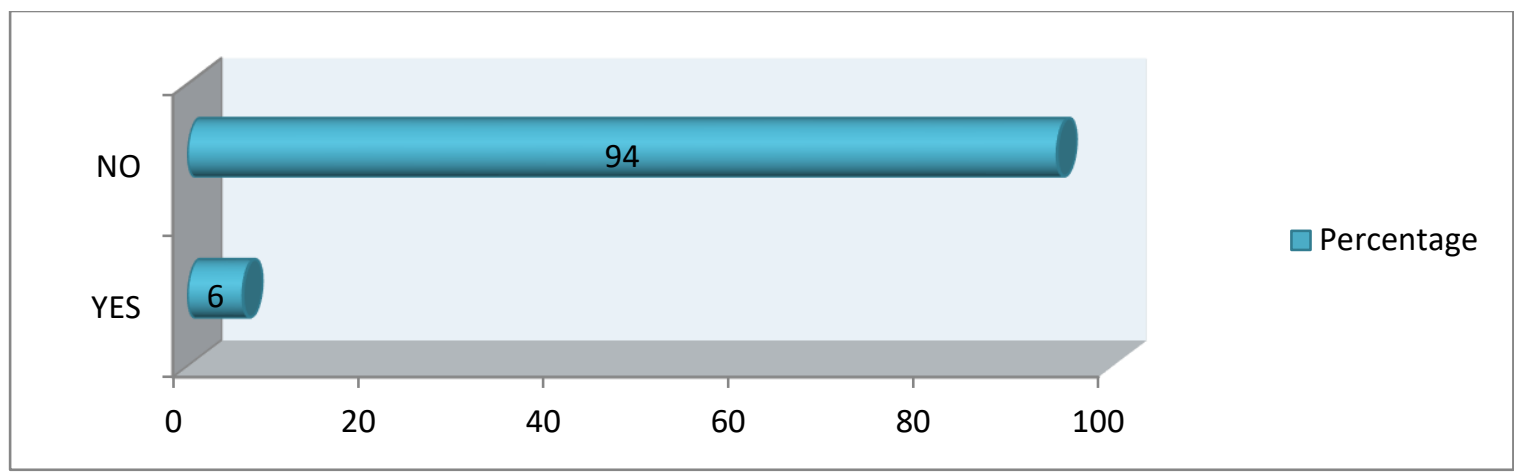

Figure 4: Availability of AT expertise

(Source: Field data, 2020.)

\subsection{Existence of national education policy specifically for students with disabilities at the university level}

Currently, there is no national education policy that is made to address the specific needs of PWD in HLIs in Tanzania (Possi \& Milinga, 2017). When asked, all eighteen (100\%) respondents responded the same. Figure 5 shows the results. The national policy on disability of 2004, the education and training policy of 2014, and the National higher education policy of 2007 state too general and do not address specific targets of education for PWD in HLIs (Possi \& Milinga, 2017). However, the Higher Education Students Loans 
Board (HESLB) Act of 2007 formalized PWD as among priorities in loan provision (Ngonyani, 2021).

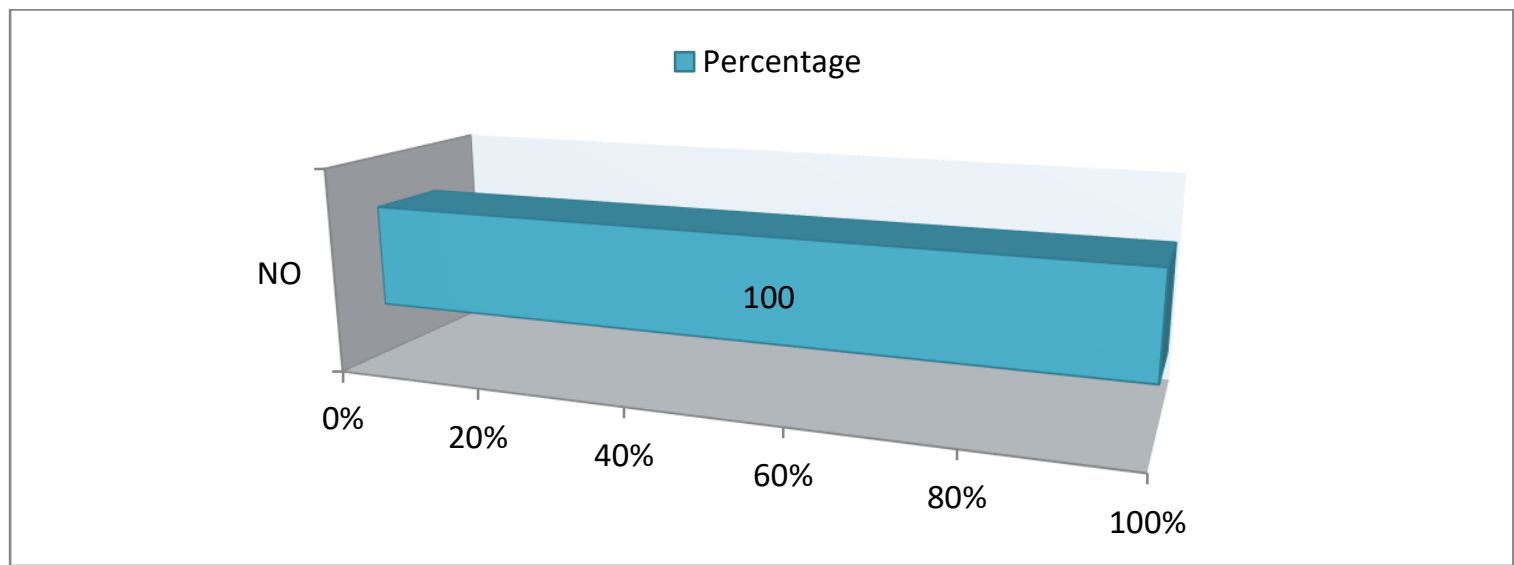

Figure 5: Existence of national education policy for students with disabilities at the university level

(Source: Field data, 2020.)

\subsection{Challenges on the use of AT among PWD in HLIs in Tanzania}

Students with disabilities faced several challenges related to the use of AT in the learning process. The responses are summarized in percentages in Figure 6.

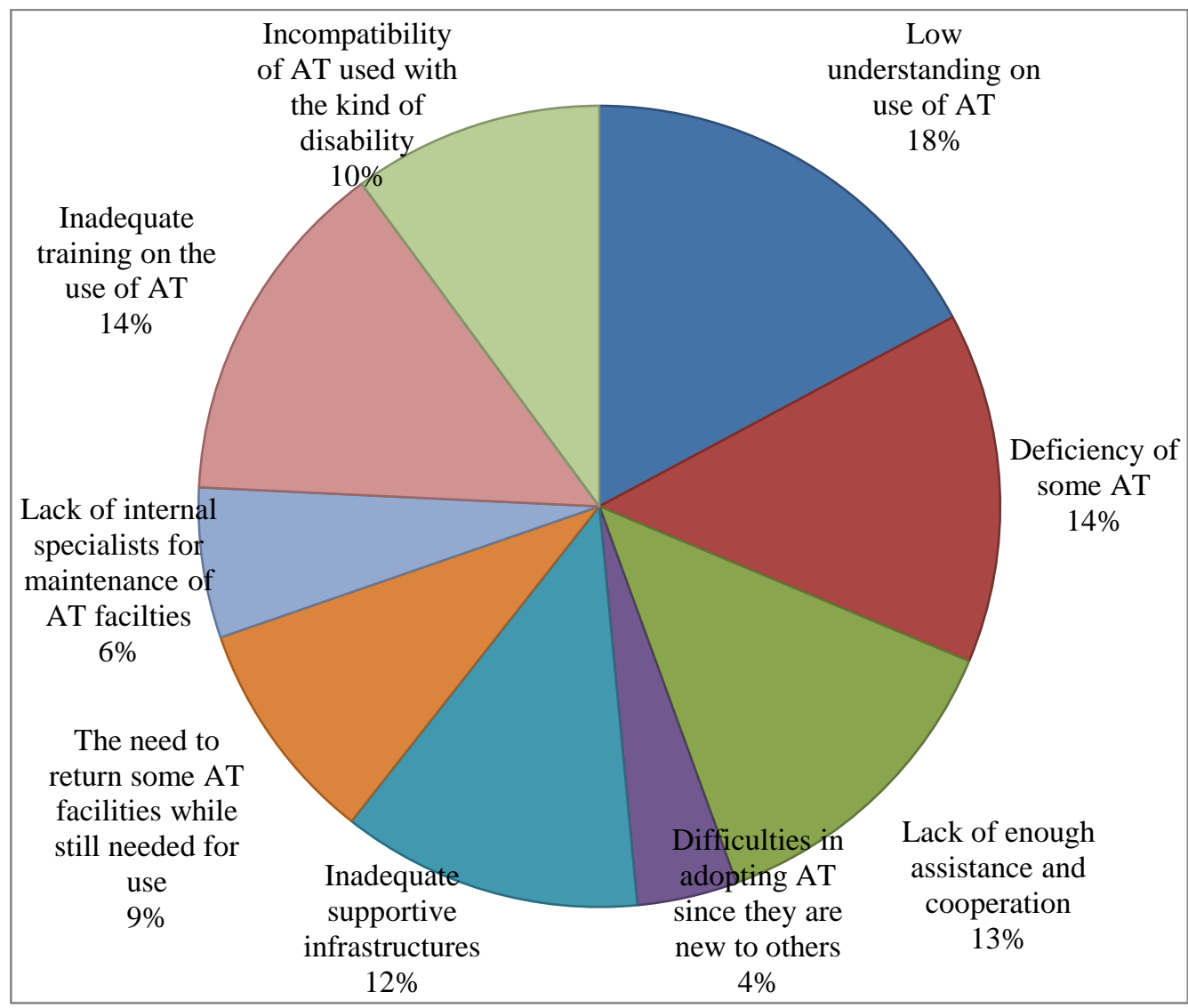

Figure 6: Challenges encountered by PWD concerning the use of AT

(Source: Field data, 2020.) 
The findings indicated that $31(18 \%)$ respondents stressed low understanding of the AT usage which was caused by insufficient training to both trainers and PWD which was also reported by twenty-four (14\%) of respondents. The invention of new AT and lack of training and the fact that some AT was only borrowed for a short time and returned afterward caused difficulties in the learning process for the PWD. Mnyanyi (2009) in his study supported this finding by adding that most special education trainers were not practical oriented and depended on on-site training which was limited. Another cause for inadequate training as reported by six $(10 \%)$ of respondents was lack of AT specialist who was responsible for training, maintenance, repair and servicing of faulted AT which may result in massive functionless devices. Wilson \& Wilson (2001) emphasized constant training, improvement, and support as the crucial elements when using and interfacing with AT.

About Twenty four (14\%) respondents reported on the deficiency of AT. The presence of faults such as tape recorders with limited storage capacity, electricity problems for power-operated devices and lack of a special translation program (NVDA) for the visually impaired in some computers made them ineffective. One respondent said:

"One day during the class, tape recorder was full unknowingly, I came to realize at the end of the lesson, I did not record the rest of the lesson".

To support this finding, Possi \& Milinga ( 2017) in their study found that most of AT were not in good working condition because there was no technician to repair the damages or fix some technical problems.

Lack of assistance and cooperation was also mentioned by twenty-three (13\%) of the respondents. To break the social and intellectual barriers PWD had to be provided with support and attention. Some isolated them thinking that they were a burden. Students noise that might interfere with the recording process and lack of responsibility from the lecturers during class session, for example movement during teaching which made it difficult for the hearing impaired who could understand by looking on lipreading, facial expressions, gestures, and written instruction. One student said,

"I concentrate on the lecturer to read her mouth movement, but she is not stationary, so I need a leader to assist me".

Another respondent added:

"I do not like the use of statements; 'it is like this', 'it looks like that' while the lecturer elaborates a certain topic because I cannot see the object which was referred."

Another student said: 
"Sometimes the noises interfere with the recording process, and I always playback many times and need assistance from a reader to sort out so that I catch the lesson well".

Kisanga et al. (2018) stressed that, before the introduction of various guidelines and initiatives to support them such as EFA and UPE, PWD was socially, physically, and academically isolated.

However inadequate supportive infrastructures were reported by twenty-one $(12 \%)$ respondents. The remoteness of some classes and stairs in most of the old buildings which were not designed inclusively example DUCE made it difficult for the physically and visually impaired to reach the classes. The fact was supported by Rao (2015) who pointed the hurdles of the PWD due to remoteness and non-inclusive structures of hostels, classes, washrooms, and canteen.

Incompatibility of AT to the kind of disability. It was reported by seventeen (10\%) respondents that, the AT tended not to comply with the type of disability. Also, some AT software or programs did not suffice their requirement thus needed assistance from a personal translator. One respondent said:

"...sometimes we visually impaired, are asked to submit a work typed on the computer while we are using braille this makes it difficult and time-consuming to translate the work from braille to computer".

Generalization of the AT used by PWD without understanding individual needs may cause misunderstanding (Richardson, et al., 2013). For example, visually impaired had different degree of disability and needed different AT to fulfill their requirements.

However, sixteen $(9 \%)$ respondents said they were required to return the AT while it was still needed for use. This might have led to low performance since they needed a particular AT for exam preparations. One respondent replied:

"I cannot forget the day that I was required to return it because I saved my notes in that AT and needed to transfer them to another portable device that did not accommodate all notes".

During their learning process, PWD must be constantly provided with AT for more practices and advancing their performance (Mnyanyi, 2007).

Furthermore, the Advancement and introduction of new technologies had implications related to acceptance and utilization. Seven (4\%) respondents mentioned that they had difficulties on use of AT because they had not used it before. Some of them did find the AT totally new; while others had used devices version different from those offered by the institution as well as those who became impaired in the course of university study. However evolving technologies made it difficult to change, for example transforming from braille to note taker. This fact was also supported by Van den Heuvel et al. (2012), that some important tasks could not be supported by any AT example 
activities related to maintaining social life because of continuous technological development.

\subsection{Solutions to the challenges among PWD through the use of AT}

There are several ways of improving the learning process for PWD, as shown in Figure 7.

Provision of frequent pieces of training was sighted by thirty-five $(20 \%)$ of the respondents. Intensive training to both PWD and their trainers would improve proper use of the device (Flanagan et al., 2013) hence reduce damages, rectifying any error incurring during AT usage, and report it immediately for further actions. It could also produce new professionals of AT and its usage as well as shaping and assisting the PWD. More than that, Tungaraza (2014) added that trainings should not only be given to PWD and their trainers, but also school administrators, therapists, school nurses, school drivers, cooks, wardens, and other Learners so that they should be aware of the needs of PWD and work together with the trainers. Twenty-eight (16\%) suggested that there must be enough AT provided to each PWD which would improve the chance to more understanding of the AT and its usage. This finding has also been mentioned by Mnyanyi (2009) that PWD could be more competent if permanently assigned with an AT. Also, the damaged AT must be substituted by new ones to maintain the ratio of the available devices and that of the PWD.

Twenty-one (12\%) respondents suggested the continuous checking, maintenance, and servicing of AT. Mwaipopo et al. (2011) supported this finding and added that such implementation would ensure that they were in good working condition and satisfy the consumers. Another $21(12 \%)$ respondents stressed the improvement of infrastructure to facilitate easy mobility for PWD and all-important resources such as libraries, hostels, washrooms, canteen. In addition to that Rao (2015) suggested the presence of inclusively and easily accessed learning environment that could meet the needs of PWD. One student said:

"I need a potential transport because the present transport 'tricycle' is limited and the hostel is located far from the classes that make me late or miss some of my classes."

However, $17(10 \%)$ suggested the increase in the number of permanent internal AT experts who would be responsible for maintenance and repair of AT. In addition to that Bouck et al. (2013) insisted on employing AT technicians instead of depending on outsourced expensive professionals. Fifteen (9\%) responded that there should be the distribution of efficient AT. If reliable and appropriate AT were given to PWD they would have felt safe and comfortable in the learning process (Kumar \& Raja, 2010).This could help them perform their everyday tasks as required. One respondent said:

"We will be completely independent and satisfied if reliable and suitable AT will be provided." 
Moreover, fifteen (9\%) respondents called for cooperation among PWD, lecturers, other learners, and the society. Lihamba et al. (2011) criticized negative or somewhat uninformed or insensitive attitudes towards PWD, which had been established by the social model of disability, and suggested a concentration of all strength towards the real needs of PWD instead of ignoring them. Ten (6\%) suggested special treatment to the PWD by considering their needs, providing them with support services, also highlighted in The National Higher Education Policy (The United Republic of Tanzania, 2007). Such services include professional sign language interpreters, note-takers, leaders, trainers, primary health care, psychological help, loans and the suitable AT. Also, the lecturers must recognize their existence and give them special attention they need.

Furthermore, seven (4\%) suggested the implementation of AT that complies with the technology change. The AT provided to PWD in Tanzania should comply with universal standards that can be applied anywhere across the globe. Moreover, Van den Heuvel et al. (2012) added that it is hard to predict what AT solution will be available shortly since technology is not stagnant.

Lastly, four $(2 \%)$ respondents pointed out the importance of considering the needs of the PWD When developing the curriculums. Tungaraza (2014) added that, since PWD learn differently, and they have different learning needs, their evaluation procedures should also be different. However, the trainers should learn how to incorporate that curriculum and implement it in their inclusive classes (Mnyanyi, 2009). Rao (2015) further suggests that the higher learning institution should not only change the physical structures where the learning process took place, but also the way whereby higher education curriculum is organized, delivered, and assessed inclusively.

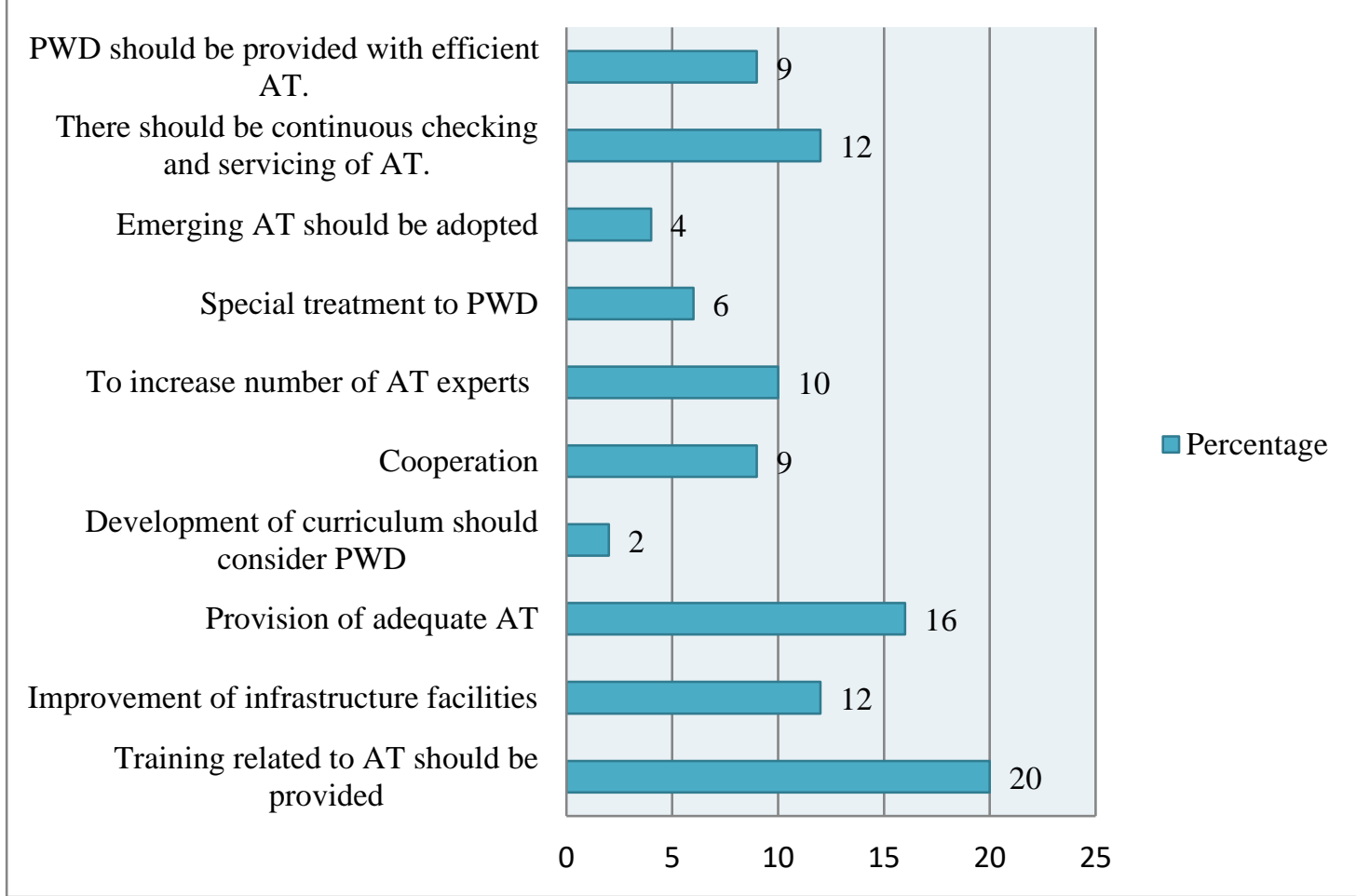

Figure 7: Solutions to the challenges among PWD through the use of AT 


\section{Conclusion and Recommendations}

\subsection{Conclusion}

The study provided a comprehensive review on assessing the Relevancy of AT used by PWD in HLIs in Tanzania as one objective of the descriptive study that examined the use of AT for PWD in HLIs in Tanzania, a case of the University of Dar es salaam. Based on the finding the researcher concluded that AT and other support services were delivered to PWD though they were not enough. Also, the institution has no permanent internal AT expert for training, maintenance servicing and repair henceforth uses outside specialists when there was a need to install a newly purchased or maintenance of faulted AT was needed. However, the pieces of training provided did not suffice the actual needs of the PWD due to advancement of technology, the need for skills to use AT and late disability, hence frequently training is needed.

\subsection{Recommendations}

Based on the findings of the study, several recommendations were pointed to various key players:

\subsubsection{The government}

It was recommended that the government should address all pointed-out concerns on issues of PWD in HLIs and find the solution. Enough budget should be allocated to purchase AT in HLIs. The government should establish specific institutions for expertise on special treatment for PWD as required.

\subsubsection{Policymakers}

On the question of policies, policymakers and stakeholders should formulate policies that are not only favourable but also viable to PWD because there are no specific policies at present addressing the issues of PWD in HLIs in Tanzania.

\subsubsection{Higher learning institutions}

It was recommended that all HLIs should be provided with suitable infrastructures (buildings and transport) to PWD and should consider PWD in their strategic plan.

\subsubsection{Researchers}

Researchers are advised to conduct more investigations on issues related to PWD in HLIs since little has been addressed in that area of specialization.

\subsubsection{Curriculum developers}

The crafting of curriculum process, issues about PWD should be considered; also all teacher training institutions should incorporate the needs of PWD in their curricular for sustainability. 


\title{
Conflict of Interest Statement
}

The authors declare that there is no conflict of interest. The study has not received any financial support. All processes followed observed the ethical standards. The letters of acceptance to conduct research were granted and knowledgeable approvals were gained from all respondents.

\begin{abstract}
About the Authors
Josephine C. Ngonyani has a Bachelor Degree in Computer Science from St. Joseph University in Tanzania (2013). In 2017 she was registered and certified as a Technical teacher by the National Council for Technical Education (NACTE) of Tanzania. She is currently finalizing Her Master of Science in ICT (MSc-ICT) at the Open University of Tanzania, researching the use of assistive technology for Persons with disabilities in higher educational institutions in Tanzania. Her job experience includes working as a tutorial assistant at Tanzania Public Service College (8 years of working experience).

Dr. Cosmas B. Mnyanyi Is a senior lecturer in educational psychology and special needs education at the Open University of Tanzania. He has over 30 years of teaching experience and has worked in disability studies for over 18 years in specifically in assistive technologies. He has been heading a section supporting students with disabilities at the Open University of Tanzania for over 10 years now. (ORCID: orcid.org/0000-0002-9391-4455 website: www.out.ac.tz)
\end{abstract}

\section{References}

Bagon, Š., Mateja, G., Starcic, A. I. (2018). Information Communication Use among students in Inclusive classrooms. International Journal of Emerging Technologies in Learning (IJET). 13(6), 56-72. DOI:10.3991/ijet.v13i06.8051

Batorowicz, B., Missiuna, C. A., \& Pollock, N. A. (2012). Technology supporting written productivity in children with learning disabilities: A critical review. Canadian Journal of Occupational Therapy, 79(4), 211-224. doi:10.2182/cjot.2012.79.4.3.

Campbell, P., Milbourne, S., Dugan, L. \& Wilcox, J. (2006). A review of evidence on practices for teaching young children to use assistive technology devices. Early childhood Special Education. 26 (1), 3-13

Chiang, H. Jacobs, K. (2010). Perceptions of Computer-based instruction system in special education: High school teachers and student views. World Journal of Education. 37 (4), 349-359

Chmiliar, L. (2007). Perspectives on assistive technology: What teachers, health professionals, and speech-language pathologists have to say. Developmental Disabilities Bulletin, 35(1), 1-17.

Chmiliar, L., \& Cheung, B. (2007). Assistive technology training for teachers - Innovation and accessibility online. Developmental Disabilities Bulletin, 35(1), 18-28.

DUCE, (2018). [https://duce.ac.tz/special-education-unit/] site visited on 7/3/2020. 
Flanagan, S., Bouck, E. G., \& Richardson, J. (2013). Middle school special education teachers' perceptions and use of assistive technology in literacy instruction. Assistive Technology, 25(1), 24-30. doi:10.1080/10400435.2012.682697.

Kisanga, D. Wambura, D. Mwalongo, F. (2018). Exploring assistive technology tools and e-learning user interface in Tanzania vocational education institutions. International Journal of Education and Development using Information and Communication Technology (IJEDICT), 14(3): 50-71.

Krantz, O. (2012). Assistive devices utilization in activities of everyday life - A proposed framework of understanding a user perspective. Disability $\mathcal{E}$ Rehabilitation; Assistive Technology, 7, 189-198

Kumar, S. \& Raja, B. (2010). Web-based Technology for children with learning difficulties. Journal of Educational Technology. 7 (1), 8-13.

Lai, P. C. (2016) Design and Security Impact on Consumers' Intention to use Single Platform Epayment, Interdisciplinary Information Sciences. 22(1), 111-122.

Lai, P. C. (2017). The Literature Review of Technology Adoption Models and Theories for the Novelty Technology. JISTEM-Journal of Information Systems and Technology Management, 14(1), 21-38.

Lee, Y., \& Vega, L. A. (2005). Perceived knowledge, attitudes and challenges of Assistive Technology use in special education. Journal of Special Education Technology, 20, 6063.

MacArthur, C. (2009). Reflections on research on writing and technology for struggling writers. Learning Disabilities Research \& Practice, 24(2), 93-103. doi:10.1111/j.15405826.2009.00283.

MacArthur, C. A., Ferretti, R. P., Okolo, C. M., \& Cavalier, A. R. (2001). Technology applications for students with literacy problems: A critical review. The Elementary School Journal, 101(3), 273-301. doi:10.1086/499669.

Marino, M. T., Marino, E. C., \& Shaw, S. F. (2006). Making informed assistive technology decisions for students with high incidence disabilities. Teaching Exceptional Children, 38(6), 18-25.

McCreadie, C. (2003). "Shower Success". Working with Older People, 7 (2), pp.25-29.

Michaels, C. A., \& McDermott, J. (2003). Assistive technology integration in special education teacher preparation: Program coordinators' perceptions of current attainment and importance. Journal of Special Education Technology, 18, 29-41.

Mnyanyi, C. B. F. (2007) Special Needs Education: some experiences from Tanzania, Journal of Instruction and Practice in Education, 2(1), 62-72.

Mnyanyi, C. B. F. (2009). Developing Teachers' Work for Improving Teaching and Learning of Children with Visual Impairment Accommodated in Ordinary Primary Schools. European Educational Research Journal. 8. 10.2304/eerj.2009.8.2.336.

Mull, C. A., \& Sitlington, P. L. (2003). The role of technology in the transition to postsecondary education of students with learning disabilities. Journal of Special Education, 37(1), 26-32. doi:10.1177/00224669030370010301. 
Mwaipopo, R. N., Lihamba, A., \& Njewele, D. C. (2011). Equity and Equality in Access to Higher Education: the experiences of students with disabilities in Tanzania. Research in Comparative and International Education. 6(4), 415-429.

Ngonyani, J. C. (2021). The use of Assistive Technology for Persons with Disabilities in Higher Learning Institutions in Tanzania: A case of University of Dar es Salaam (Unpublished master's thesis). Open University of Tanzania, Tanzania.

Okolo, C. M., \& Diedrich, J. (2014). Twenty-five years later: How is technology used in the education of students with disabilities? Results of a state wide study. Journal of Special Education Technology, 29(1), 1-20.

Patton, M. Q. (1990). Quantitative Evaluation and Research Methods (2nd ed): Designing Qualitative study. Newbury Park, CA: sage, 552pp.

Possi, M. K., Millinga, J. R. (2017). Special and Inclusive Education in Tanzania: Reminiscing the Past, Building the Future. Educational Process: International Journal, 6(4), 55-73.

Rao, N. A. (2015). Perceptions of Students with Disabilities on Support Services Provided in Higher Education Institutions. 10.13140/RG.2.2.34054.22088.

Specht, J., Howell, G., \& Young, G. (2007). Students with special education needs and their use of assistive technology during the transition to secondary school. Childhood Education, International Focus Issue, 83, 385-389. doi:10.1080/00094056.2007.10522956.

Tungaraza, F. 2012. Inclusive education in Tanzania: Are all learners identified and their needs known? A Journal of Contemporary Research, 9(3), 17-27.

Tungaraza, F. D. (2014).Training Teachers in Special Needs Education in Tanzania: A Long and Challenging Ordeal to Inclusion. African Journals Online (AJOL), 16: 4960.

UNESCO, 2009. Policy guidelines on inclusion in education, Paris: United Nations Educational Scientific and Cultural Organisations. France: UNESCO.

URT, 1998. The Tanzania Development Vision 2025. Tanzania: Planning Commission.

United Republic of Tanzania (2004) National Policy on Disability. Dar es Salaam: Ministry of Labour, Youth Development and Sports.

United Republic of Tanzania (2007) The National Higher Education Policy. Dar es Salaam: Ministry of Higher Education, Science and Technology.

Van den Heuvel, E., Jowitt, F. \& McIntyre, A. (2012). Awareness, requirements and barriers to use of assistive technology designed to enable independence of people suffering from dementia (ATD). Technology \& Disability, 24, 139-148.

Wessels, R., Dijcks, B., Soede, M., Gelderblom, G.J. \& De Witte, L. (2003). Non-use of provided assistive technology devices, a literature overview. Technology $\mathcal{E}$ Disability, 15, 231-238.

WHO (2015). Assistive Technology for Children with Disabilities: Creating Opportunities for Education, Inclusion and Participation. A discussion paper.

Wilson, J., \& Wilson, C. (2001). Embodied Rhetoric - Disability in Language and Culture. Illinois: Southern Illinois University. 

be applied to their work. Under the terms of this license, no permission is required from the author(s) or publisher for members of the community to copy, distribute, transmit or adapt the article content, providing a proper, prominent and unambiguous attribution to the authors in a manner that makes clear that the materials are being reused under permission of a Creative Commons License. Views, opinions and conclusions expressed in this research article are views, opinions and conclusions of the author(s). Open Access Publishing Group and European Journal of Special Education Research shall not be responsible or answerable for any loss, damage or liability caused in relation to/arising out of conflict of interests, copyright violations and inappropriate or inaccurate use of any kind content related or integrated on the research work. All the published works are meeting the Open Access Publishing requirements and can be freely accessed, shared, modified, distributed and used in educational, commercial and non-commercial purposes under a Creative Commons Attribution 4.0 International License (CC BY 4.0). 